\title{
Long-term safety profile of tolvaptan in autosomal dominant polycystic kidney disease patients:TEMPO Extension Japan Trial [Corrigendum]
}

\section{Muto S, Okada T, Yasuda M, et al. Drug Healthc Patient Saf. 2017;9:93-104.}

On page 97, 'Discussion' section, lines 10-13, left column, the sentence: 'Similarly, placebo patients who crossed over onto active treatment discontinued at a similar rate (24.0\%), while those who continued on tolvaptan treatment discontinued at a much lower rate (11.8\%)' should read: 'Similarly, placebo patients who crossed over onto active treatment discontinued at a similar rate $(26.0 \%)$, while those who continued on tolvaptan treatment discontinued at a much lower rate $(10.6 \%)$ '.
On page 101, Figure 6 , the number of patients of ' $\mathrm{Com}$ pleted trial' in the TEMPO Extension Japan trial should be revised from ' $n=75$ ' to ' $n=76$ ', and 'Withdrawal rate' should also be revised from ' $11.8 \%$ ' to ' $10.6 \%$ ' in the allocated to tolvaptan in TEMPO 3:4 trial. The number of patients of 'Completed trial' in TEMPO Extension Japan trial should be revised from ' $n=38$ ' to ' $n=37$ ', and 'Withdrawal rate' should also be revised from ' $24.0 \%$ ' to ' $26.0 \%$ ' in the allocated to placebo in TEMPO 3:4 trial. The correct figure is shown here.
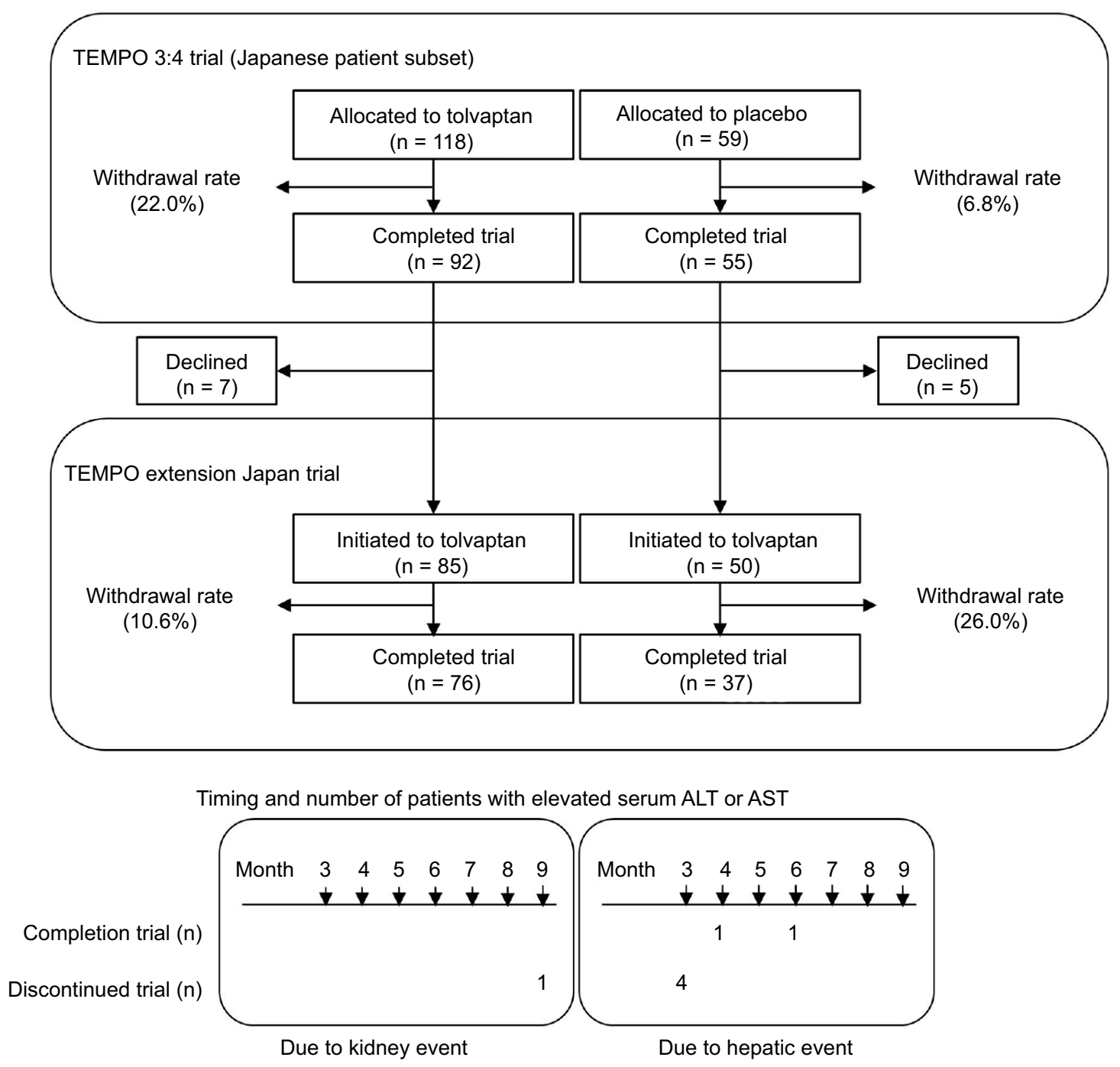
Drug, Healthcare and Patient Safety

Dovepress

\section{Publish your work in this journal}

Drug, Healthcare and Patient Safety is an international, peer-reviewed open access journal exploring patient safety issues in the healthcare continuum from diagnostic and screening interventions through to treatment, drug therapy and surgery. The journal is characterized by the rapid reporting of reviews, original research, clinical, epidemiological and

post-marketing surveillance studies, risk management, health literacy and educational programs across all areas of healthcare delivery. The manuscript management system is completely online and includes a very quick and fair peer-review system. Visit http://www.dovepress.com/ testimonials.php to read real quotes from published authors.

Submit your manuscript here: https://www.dovepress.com/drug-healthcare-and-patient-safety-journal 